\title{
SLEEP HABITS AMONG FIRST YEAR MEDICAL STUDENTS
}

\author{
Neera Goel1, Varun Malhotra ${ }^{2}$, Yogesh Tripathi ${ }^{3}$
}

${ }^{1}$ Associate Professor, Department of Physiology, Santosh Medical College, Ghaziabad, Uttar Pradesh. 2 Professor and HOD, Department of Physiology, Santosh Medical College, Ghaziabad, Uttar Pradesh. 3 Professor and Dean, Department of Physiology, Santosh Medical College, Ghaziabad, Uttar Pradesh.

\section{ABSTRACT}

Sleep is part of the rhythm of life; without a good sleep the mind is less adaptive, mood is altered and the body loses the ability to refresh. The sleep-wake cycle of medical students is quite different and sleep deprivation, poor sleep quality, occurrence of napping episodes during the day. This study was designed to assess sleep habits in first year medical students.

\section{MATERIAL AND METHODS}

Participants of this study were healthy medical students of first year MBBS course of Santosh Medical College, Ghaziabad. A self-administered questionnaire was distributed to students to assess age, sleep-wake schedule, naps, total sleep time at night, possible factors affecting bedtime and daytime sleepiness using Epworth Sleepiness Scale (ESS) and quality of sleep by using Pittsburgh Sleep Quality Index (PSQI).

\section{RESULT}

The final study included 65 students, total sleep time at night+ nap of the whole group was $5.5 \pm 1.6$ hours. Seven students $(10 \%)$ were defined to have Excessive Day Time Sleepiness (EDS) based on ESS score of $>10$. Also $70.2 \%$ students reported napping during the day time and 60\% students have poor sleep quality (PSQI score $>5$ ).

\section{CONCLUSION}

Analysis of the sleep habit of medical students revealed that this group is sleep deprived, which in turn may affect their academic performance.

\section{KEYWORDS}

Sleep, Epworth Sleepiness Scale (ESS), Pittsburgh Sleep Quality Index (PSQI), Sleep-Wake Schedule.

HOW TO CITE THIS ARTICLE: Goel N, Malhotra V, Tripathi Y. Sleep habits among first year medical students. J. Evolution Med. Dent. Sci. 2016;5(38):2276-2278, DOI: 10.14260/jemds/2016/529

\section{INTRODUCTION}

Sleep is an important component of normal human physiology. It serves a restorative homeostatic function and appears to be crucial for normal thermoregulation and energy conservation.(1) College student generally is a healthy population with few sleep-related complaints.(2) As a group, they are prone to psychological and physical stress due to the transitional nature of college life.(3) Medical students are submitted to a lot of pressure due to academic demands. Moreover, the sleep-wake cycle of the students is characterized by insufficient sleep duration, delayed sleep onset and occurrence of napping episodes during the day.(4)

Sleep deprivation can be harmful to students. A high correlation has been demonstrated between sleep duration and performance in some activities as well as subjective alertness; sleep deprivation can be harmful to students.(5) Sleep and sleep related health issues in this period of life also have received relatively little attention despite the presence of sleep complaints and disorders. (6)

The importance of sleep duration was also found, which demonstrated correlation between sleep deprivation and academic performance in medical students.(7)

Financial or Other, Competing Interest: None.

Submission 28-03-2016, Peer Review 23-04-2016,

Acceptance 29-04-2016, Published 10-05-2016.

Corresponding Author:

Dr. Neera Goel,

H. N. 31, Sect-6, Chiranjeev Vihar,

Ghaziabad, Uttar Pradesh.

E-mail: neera.goel15@gmail.com

DOI: $10.14260 /$ jemds/2016/529
One of the important functions of sleep is to preserve and optimize waking brain function. Sleep deprivation in humans and animals is associated with decrease in subjective alertness, vigilance and decision making. $(8,9,10)$

Sleep may affect not only cognitive functions, but also the ability to accumulate experience and to learn both in cognitive and affective domains.(11,12) Sleep deprivation is associated with impaired glucose metabolism and relative insulin insensitivity. Sleep deprivation is also associated with altered measure of immune function, suggesting that sleep may play important host defense roles as well.(13)

This study was designed to assess sleep habits and quality of sleep in first year medical students and describe their sleep habits during weekdays and compare our results to published data.

\section{MATERIAL AND METHODS}

In the present study, we investigated the pattern of sleepwake cycle in a natural condition. The subjects were first year medical students from Santosh Medical College, Ghaziabad, (UP). The participants filled out an identification form with their general information and signed a written informed consent form.

Exclusion criteria for subjects were students during this period did not have any exams. Students who are repeaters, those with chronic diseases, sleep disorders, drank alcohol were excluded.

Inclusion criteria for subjects were healthy Students willing to participate, not taking any medication, sibling also not taking any medication for any major sleep disorders. 
A self-administered questionnaire was designed regarding age, sleep-wake schedule, naps and day time sleepiness using Epworth Sleepiness Scale (ESS).(14) It consists of 8 different situations and activities that are often part of everyday life. The total ESS score is a measure of the average sleep propensity of falling asleep in those conditions. The total score ranges from $0-24$. The upper limit of normal based on previous work in healthy adults is estimated to be 10.(14) Hence, an ESS scores of $>10$ indicate daytime sleepiness. They also answered Pittsburgh sleep quality index (PSQI).(15) which contains 10 questions related to normal sleep habits. A value above 5 on this test indicates a poor sleep quality. To study the sleep habits, we used a sleep diary indicating times of waking and sleeping. This subjective record is frequently used in sleep related research and is highly correlated with polysomnography and Actigraphy measures. $(16,17)$

Data were expressed as mean $\pm \mathrm{SD}$ and also calculated percentage.

\section{RESULT}

Of the 80 questionnaires distributed 65 (82\%) were returned.

\begin{tabular}{|c|c|}
\hline Characteristics & Number $=65$ \\
\hline Age & $20 \pm 0.8$ \\
\hline TST & $4.6 \pm 1.6 \mathrm{~h}$ \\
\hline Students who nap (\%) & $70.2 \%$ \\
\hline Duration of nap (s) & $1.1 \pm 0.6 \mathrm{~h}$ \\
\hline TST+ nap & $5.5 \pm 1.6 \mathrm{~h}$ \\
\hline ESS score & $5.4 \pm 2.8$ \\
\hline$\%$ of Students, ESS score $>10$ & $10 \%$ \\
\hline Subjective sleepiness & $12 \%$ \\
\hline PSQI score $>5$ & $60 \%$ \\
\hline Mean PSQI & 7.48 \\
\hline Mean PSQI $>5$ & $9.12 \pm 3.51$ \\
\hline
\end{tabular}

TST=Total Sleep Time, ESS=Epworth Sleepiness Scale, PSQI=Pittsburgh Sleep Quality Index.

Mean age of the participants was $20 \pm 0.8$ years.

Table 1 summarizes the main sleep characteristics of $1^{\text {st }}$ year medical students. The TST+ nap of students were $5.5 \pm 1.6 \mathrm{~h}$. The TST was $4.6 \pm 1.6 \mathrm{~h}$. The mean ESS score was $5.4 \pm 2.8$. The $10 \%$ students were defined to have Excessive Day Time Sleepiness (EDS) based on ESS score of $>10$ and $70.2 \%$ students nap and $12 \%$ reported the feeling of sleepiness on direct questioning. Students with EDS and low TST compensated that by taking naps during daytime.

As depicted in the table, out of 65 students 40 students (60\%) have PSQI $>5$ with mean $9.12 \pm 3.51$ and mean PSQI for all the students were 7.48. PSQI $>5$ indicates poor sleep quality and in the present study students have PSQI $>5$ suggesting poor sleep quality.

\section{DISCUSSION}

We all need sleep to be able to function the next day. However, the unanswered question is, how much sleep do we need? Sleep researchers do not seem to agree on how much we should sleep. With the new civilization, sleep restriction has become a global problem.(18) Most young adults report sleeping on average approximately $7.5 \mathrm{~h}$ a night on weekday nights and slightly longer, $8.5 \mathrm{~h}$ on weekend nights.(19)
Medical students are a special group of young adults whose life constraints can cause irregular sleep habits or shortening of mean sleep length compared with individual's sleep need. There is some evidence in literature supporting the hypothesis that sleep difficulties and deprivation can significantly impair student's academic performance.(20) Total sleep time in our studied group was low compared to previously reported studies. In a recently published study carried out among psychology students. ${ }^{(21)}$

Our students slept much less (TST $4.6 \pm 1.6 \mathrm{hr}$.) and tried to compensate by taking daytime naps (TST+nap $=5.5 \pm 1.6 \mathrm{~h}$ ). Even then the total time slept was much less than that of normal individuals at this age group (7-9 $\mathrm{h}$ for age group 1825 yrs.).(22) In Saudi healthcare workers with a mean age of 32 yrs., reported a total sleep time of $6.3 \mathrm{hrs}$. only.(23)

Sleep deprivation is associated with a variety of adverse consequences that can be potentially life threatening.(24) Moreover, sleep deprivation can result in significant changes in cognitive functioning, short term memory and concentration. (25)

Another interesting finding is the high percentage students (70.2\%) who nap during the day time. Our findings concurred with other studies conducted in India, $68.5 \%$ boys were taking naps.(26,27) In Saudi showed that $88 \%$ of Saudi males nap during the daytime.(23) In another study in Saudi on medical students showed that $83.3 \%$ students nap during the daytime. It seems that napping during the daytime is related to cultural background.(28) In a survey conducted among human sciences faculty students in Morocco, had shown a much lower percentage of daytime napping (41\%).(29) An increase in the percentage of those who nap may indirectly reflect an increased bodily need or wish for more sleep due to sleep deprivation.(30)

Daytime sleepiness was assessed by using the ESS.(14,31,32) $10 \%$ of our students scored $>10$ indicating increased daytime sleepiness. In Saudi, $20 \%$ of subjects scored $>10 .{ }^{(23,28)}$ Short sleeping time on weekdays combined with an irregular sleep wake schedule during the weekends is a more common predictor of daytime sleepiness. (33)

PSQI measures overall sleep quality and value above 5 indicates poor sleep quality; $60 \%$ of our student's PSQI was $>5$ (poor sleep quality). In other study medical students residing in home have PSQI $>5$ are $55 \%$ and in hostel group PSQI > 5 are 70.5\%.(34) In other study, $69.5 \%$ medical students had a disturbed and poor sleep quality. ${ }^{(35,36)}$ Another study on medical students showed that medical students had delayed type sleep patterns and 5\% suffered from clinically significant insomnia.(37) Our subjects were medical students who like most medical students were submitted to demanding curricular schedule. The large number of classes and the need devote much time to studying contributed to the poor sleep quality observed in this group of students.

\section{CONCLUSION}

Analysis of sleep pattern of first year medical students revealed that this group is sleep deprived, which in turn might affect their academic performance. Further study is needed to know the effect of sleep deprivation or poor sleep quality on performance. Students need to regularize their routine keeping a balance with right eating, recreation, studies and sleeping. Counselling sessions were held at Santosh Medical College to advise them individually on living a balanced life. 


\section{Limitation of Study}

Because of unavailability of polysomnograph in the department, EEG recording of subjects was not taken which can verify subjective questionnaire based data. Further study on medical students of different medical colleges need to require knowing their sleep habits.

\section{ACKNOWLEDGEMENT}

We would like to thank all the first year medical students who supported us for collection of data.

\section{REFERENCES}

1. Kaplan HI, Sadock BJ. Synopsis of psychiatry. Baltimore (MD): Williams and Wikins 1998;8th ed:737-41.

2. Pilchor JJ, Schoeling SE, Prosansky CM. Self-reported sleep habits as predictors of subjective sleepiness. Behav Med 2000;25(4):161-8.

3. Ross SE, Niebling BC, Heckert TM. Sources of stress among college students. College student journal 1999;33(2):312-7.

4. Jean-Louis G, von Gizycky H, Zizi F, et al. Mood states and sleepiness in students' influences of age, sex, habitual sleep and substances use. Perceptual and motor skills 1998;87(2):507-12.

5. Jewelt ME, Dijik DJ, Kronauer RE, et al. Dose response relationship between sleep duration and human psychomotor vigilance and subjective alertness. Sleep 1999;22(2):171-9.

6. Bijwadia J, Dexter D. The student with sleep complaints, In: Lee-chiong T, editor. Sleep: a comprehensive hand book. Hoboken (NJ): John Wiley \& sons' inc. 2006;959-63.

7. Medeiros AL, Mendes DBF, Lima PF, et al. The relationship between sleep wake cycle and academic performance in medical students. Biological Rhythm Research 2001;32(2):263-70.

8. Belenky G, Wesensten NJ, Thorne DR, et al. Pattern of performance degradation and restoration during sleep restriction and subsequent recovery: a sleep doseresponse study. J sleep Res 2003;12(1):1-12.

9. Harrison Y, Horne JA. The impact of sleep deprivation on decision making: a review. J exp psycho Appl 2000;6(3):236-49.

10. Pilcher JJ, Huffcutt AI. Effect of sleep deprivation on performance: a meta analysis. Sleep 1996;19(4):318-26.

11. Stickgold R, Whidbee D, Schirmir B, et al. Visual discrimination test improvement: a multistep process occurring during sleep. J Cogn Neuro sci 2000;12(2):24654.

12. Nifzinger EA, Mintun MA, Wiseman M, et al. Forebrain activation in REM sleep: an FDG PET study. Brain Res 1997;770(1-2):192-201.

13. Spiegel K, Sheriden JF, Van Cauter E. Effect of sleep deprivation on response to immunization. JAMA 2002;288(12):1471-2.

14. Johns MW. A new method for measuring daytime sleepiness: the epworth sleepiness scale. Sleep 1991;14(6):540-5.

15. Buysee DJ, Reynolds CF, Monk TH, et al. The Pittsburgh sleep quality index: a new instrument for psychiatric practice and research. Psychiatric Research 1989;28(2):193-213.

16. Lockley SW, Skene DJ, Arendt J. Comparison between subjective and acti graphic measurement of sleep and sleep rhythms. Journal of Sleep Research 1999;8(3):17583.
17. Usui A, Ishizuka Y, Obtinata I, et al. Validity of sleep log compared with actigraphic sleep wake state II. Psychiatry and clinical Neuro Sciences 1993;53:183-4.

18. Kryger M. Is society sleep deprived? Sleep 1995;18:901.

19. Carskadon MA, Dement WC. Normal human sleep: an overview. In Kryger $M$, Roth $\mathrm{T}$, Dement $\mathrm{W}$, editors. Principles and practice of sleep medicine. Philadelphia (PA): Saunders WB. 1994;2nd ed:16-25.

20. Lack LC. Delayed sleep and sleep loss in university students. J Am Coll Health 1986;35(3):105-10.

21. Buboltz WC, Brown F, Soper B. Sleep habits and patterns of college students: a preliminary study. J Am Coll Health 2001;50(3):131-5.

22. Max Hirshkowitz, Kaitlyn Whiton, Steven M, et al. Updated sleep duration recommendations: final report. Sleep health journal of the National Sleep foundation 2015;1(4):233-43.

23. Wali SO, Krayem AB, Samman YS, et al. Sleep disorders in Saudi health care workers. Ann Saudi Med 1991;19:406-9.

24. Reyner LA, Horne JA. Falling asleep whilst driving: are drivers aware of prior sleepiness? Int J Legal Med 1998;111(3):120-3.

25. Johnson LC. Sleep deprivation and performance. In: Biological Rhythms, Sleep and Performance. Webb WB editor. New York (NY): John Wiley \& sons; 1982;111-42.

26. Patil R, Mittal A, Raghavia, et al. A study of sleep habits and disorders among school students of Pondicherry. Journal of clinical and diagnostic research 2010;4(1):2036-40.

27. Gupta R, Bhatia MS, Chhabra V, et al. Sleep patterns of urban school-going adolescents. Indian paediatr 2008;45(3):183-9.

28. Ahmed S Bahamman, Omar K AL-Khairy, Ahmed A ALTaweel. Sleep habits and patterns among medical students. Neurosciences 2005;10(2):159-62.

29. Taoudi M, Roky R, Toufiq J, et al. Epidemiological study: chronotype and daytime sleepiness before and during Ramadan. Therapie 1999;54(5):567-72.

30. Ferrara M, Gennaro LD. How much sleep do we need? Sleep Med Rev 2001;5(2):155-79.

31. Johns MW. Reliability and factor analysis of the epworth sleepiness scale. Sleep 1992;15(4):376-81.

32. Johns MW. Sleepiness in different situations measured by the epworth sleepiness scale. Sleep 1994;17(8):703-10.

33. Saarenpaa-Heikkila OA, Rintahaka PJ, Laippala PJ, et al. Subjective daytime sleepiness and related prediction in finnish school children. Sleep and Hypnosis 2000;2:13946.

34. Nita J Ninama, Jaydeep K. Sleep wake pattern analysis. NHL Journal of Medical Sciences 2012;1(1):32-6.

35. Mohammed Alsaggaf, Siraj Wali, Mohammed Alsager, et al. Sleep disturbances among medical students at clinical years. European Respiratory Journal 2014;44(58):212-6

36. Mohammed Chanchal Azad, Kristin Fraser, Nahid Rumana, et al. Sleep disturbances among medical students: a global perspective. Journal of Clinical Sleep Medicine 2015;11(1):69-74.

37. Joshi K, Mishra D, Dubey H, et al. Sleep pattern and insomnia among medical students. Effect of gender and dysfunctional beliefs and attitude about sleep. Sonologie 2015;19(3):205-11. 